Finally, in addition to advocacy of guidance in wage policy by pronouncements of economic planning, the one principle suggested by Mrs. Wootton, that of equality, appears to spring from a particular set of social and political beliefs rather than from any practical consideration of the unquestionably urgent problems involved in the present wages situation in Great Britain.

N. S. Ross

\section{PHYSICS IN ONE VOLUME}

\section{Textbook of Physics}

Edited by R. Kronig, in collaboration with J. De Boer, H. C. Burger, P. H. Van Cittert, C. J. Gorter, A. C. S. Van Heel, P. Van Der Leeden and G. J. Sizoo, with biographical notes and tables by J. Korringa. (Translated from the Third Dutch Edition published in 1951.) Pp. $x v+856$. (London: Pergamon Press, Ltd.; New York: Interscience Publishers, Inc., 1954.) 70s. net. DISINCLINATION to believe that he has
book has often persuaded the reviewer to hope for
a single comprehensive text-book of physics which
could be safely recommended to students and which
could be used as an oceasional refresher for himself-
now happily beyond active service in examinations.

This English translation of a very successful textbook written by a group of Dutch physicists during the Second World War is probably the most ambitious attempt yet made at providing in one volume an account of physics as a whole at a reasonably advanced level. It would be easy to make criticisms of detail or complaints about particular omissions ; but a more appropriate treatment-which this book deserves-would be to attempt to explain what it does and doss not succeed in doing.

First, as would be guessed from the names of the contributors, the treatment is of high quality. Its level is roughly that which an honours student might aim to reach at the end of his second year; it would not be adequate for a third year in which any specialization was permitted. It is modern in outlook on the whole ; for example, in discussing elasticity it mentions interatomic forces, but does not describe all the variations possible in the measuremont of surface tension. It does not deal only with theoretical principles, but gets down to such practical details as the design of optical instruments. In general-though not everywhere-the phenomenological description is placed first; there are, for example, fifty pages on vibrations and waves early in the book. Unusual features include a section on modical physics and a collection of biographies of famous physioists.

However, the final and perhaps inevitable verdict must be that too much of the matter has been overcondensed. Perhaps two volumes really are necessary. To take a few examples at random : the cyclotron is dismissed in half a page, the Linde method of liquefying gases in two lines, infra-red spectroseopy in two separated paragraphs, piezo-electricity and ultrasonics in half a page. In the first chapter, in which an account is given of the objects and methods of physics, a discussion of errors is given which occupies only half a page, and an even shorter discussion of graphical methods. To be frank, one cannot imagine a student deriving much from such abbreviated accounts unless he is also pursuing a normal course of physics and has access to other books. In other words, this book must be regarded as additional reading. In this capacity it would be greatly stimulating to a serious student of physics. Within these limits, the book is about as good as one written by a group of authors could be, and probably better than one author could hope to write.

The diagrams are excellent, and the writing is free from eccentricities often found in translated work. The price, though high, is probably-in terms of pence per word-a good deal lower than the presentday average.

G. O. JONES

\section{GLOSSARY OF COALS}

\section{Coals and Bitumens and Related Fossil Carbon- aceous Substances}

Nomenclature and Classification. By Dr. S. I. Tomkeieff. Pp. $v+122$. (London: Pergamon Press, Ltd., 1954.) 17s. 6d. net.

GLOSSARY of this wide and unsystematic A subject has long been needed, and yet has never been mado; it is admirable to have it now. Dr. S. I. Tomkeieff's book contains some thirteon hundred terms, of which all but about two hundred relate to coal. The body of the book lists these alphabetically, with short definitions and references. This is followed by a series of synoptic tables and some diagrams, which give schematic order to the bewildering variety of names and substances. The methods of these classifications are explained in a short introduction.

Dr. Tomkeieff has done his work well. Where so much of the matter is traditional and local, gaps can of course be found, and there are some oddities of usage. But the book is a remarkable collection across a multitude of dialects and even languagesthere are nearly two hundred terms in some twenty foreign languages.

The interests of the author are those of the geologist rather than, say, the coal chemist, and in this respect the book falls short of the needs of the latter. For example, such important technical terms as 'volatile content' and 'carbon ratio' are defined in ways which are no longer the best standard practice. There is no classification of coals by the parameter of their ranks; and, most serious, the important modern work on the physical and chemical structure of coals is not mentioned. Outstanding progress has been made during the pest few years in understanding the properties of different coals, by deductions made from their examination by X-ray, infra-red, and other physical methods. These researches offer the best promise for bringing order of a fundamental kind into the present empirical classifications; and the neglect of such ideas in this book is therefore regrettable.

The next edition would be greatly strengthened by including in the introduction a systematic account of modern physical and chemical theories of coal structure, and by adding to the synoptic tables and diagrams a classification based on them. In its present form, Dr. Tomkeieff's book is thoroughly useful ; with these additions, it would become indispensable to all students of coal and allied substances.

J. BRoNowski 